\title{
Dealing with Isolation Feelings in IS Doctoral Programs
}

\author{
Azad Ali \\ Indiana University of Pennsylvania \\ Indiana, PA, USA
}

azad.ali@iup.edu

\author{
Frederick Kohun \\ Robert Morris University, \\ Pittsburg, PA, USA
}

\author{
kohun@rmu.edu
}

\begin{abstract}
This paper discusses the feeling of isolation among doctoral students; its' origin and the effect it has on the decision of the students to leave doctoral programs. The paper explains the development of isolation feeling within four stages of completing the program. It explains how each stage contributes to increasing the feeling of isolation among the students and then suggests counter measures to this feeling. Last, the paper presents the experience of a particular university located in Western Pennsylvania; the doctoral program of Information Systems and Communications (DISC) at Robert Morris University (RMU) that has been able to graduate students at a rate that is substantially higher than the national average.
\end{abstract}

Keywords: Information System Doctorates, Isolation feelings, Doctoral attrition

\section{Introduction}

The high rate of attrition (or drop-out) among doctoral students has been the subject of research in numerous literature. Most of the literature agree on the severity of this problem and the effect it has on students as well as on doctoral programs in general (Bowen \& Rudenstine 1992; Hawlery, 2003; Lovitts, 2001). A number of studies found different factors that contribute to increasing the rate of attrition among doctoral students. Some of these factors are directly related to the students themselves while others are related to the design and structure of the doctoral programs as well as the demographic specifics of their student population (Bourner, Bowden, \& Laing, 2001; Hockey, 1994; Lewis, Ginsberg, Davies, \& Smith, 2004; Mehmet \& Ekrem, 2000).

The feeling of Isolation among doctoral students is a major factor that contributes to the high attrition rate at doctoral programs. Yet despite this recognition, the feeling of isolation has yet to be addressed fully in the design of some doctoral programs. In other words, most programs do not include specific design features that help to handle this feeling among matriculated students (Bess, 1978; Hawlery, 2003; Lovitts \& Nelson, 2000).

Material published as part of this journal, either on-line or in print, is copyrighted by the Informing Science Institute. Permission to make digital or paper copy of part or all of these works for personal or classroom use is granted without fee provided that the copies are not made or distributed for profit or commercial advantage AND that copies 1) bear this notice in full and 2) give the full citation on the first page. It is permissible to abstract these works so long as credit is given. To copy in all other cases or to republish or to post on a server or to redistribute to lists requires specific permission and payment of a fee. Contact Publisher@InformingScience.org to request redistribution permission.
This paper provides a broader explanation about isolation feelings among doctoral students and how it contributes to the rising rate of doctoral attrition. The paper is divided into five sections. The first section explains about attrition rates in doctoral programs. Section two elaborates on the feelings of isolation and its' formation. The third section suggests 
counter measures to isolation feelings as introduced from the practical experience of other universities. Section four highlights the design issues of one doctoral program (Robert Morris University, 2004) that was able to achieve a graduation rate that is substantially higher than the national average. Finally, the fifth section tackles the issue of doctoral program quality and suggests that doctoral programs can be designed in a way that deals with the issue of isolation without jeopardizing the quality of the program.

\section{About Doctoral Attrition}

Doctoral student attrition generally refers to when students drop out of their doctoral program prior to completing their degrees. This includes the students who do not finish their dissertations known as ABD's. Attrition from doctoral programs happens at various stages in the process of obtaining the degree. It could take place at the early stages when the student has less investment in the process; or it could happen near the end of the doctoral program at the dissertation stage when the student is immersed in the program and the negative consequence of dropping out may be more substantial.

The problem of doctoral student attrition is a well-documented and has been discussed in various studies. Yet, despite the extensive coverage, this problem receives little attention in doctoral programs at various colleges and universities. Some termed this problem of doctoral student attrition as the "invisible problem" because the students drop out of the program silently without making much noise. Barbara Lovitts (2001) explains about this:

"To say that doctoral attrition is one of academe's best kept secrets would be to speak a fallacy. The statement would only be true if the attrition rate were a guarded secret. It's not. The situation is worse than that. For large segments of the country's faculty and administrators, the problem does not exist because the problem - and the student who leaves - is largely invisible (p 1)".

The invisibility part of the problem according to the above statement is related to the fact that doctoral students leave the program silently and become one of those labeled ABDs. Thus, leaving without making much noise may contribute to the perception that the students departed due to other factors related to the students themselves.

Because of this invisibility problem of doctoral attrition, little care has been given by doctoral programs to question or understand why students are dropping out. Some faculty do not even have an idea about the severity of this problem and get astonished when they learn about the attrition rate among doctoral students (Hawlery, 2003; Lovitts \& Nelson, 2000).

\section{Doctoral Attrition - Numbers}

The exact number of the students annually dropping out of doctoral programs across colleges and universities is a difficult task to undertake for a few reasons. First, students may drop out at various stages of the program, whether they are officially enrolled in the program or not; thus making it hard to distinguish whether the student is enrolled in the program or not. Second, the length of time it takes to complete the program is often unspecified. As a result, some students can spend years after finishing their course work waiting to complete their dissertation. So it is not known, at this stage, whether these students are still working on their dissertations or if they have decided to leave the program. And third, there are no national statistics of published data about doctoral attrition (Lovitts, 2001).

Despite these difficulties, various studies point to a particular number that they estimate as the percentage of students dropping out at various stages of doctoral programs. Most the studies that were reviewed here put the number at $50 \%$ as the percentage of doctoral students dropping out of 
the program after they start it (Lazerson, 2003; Lovitts \& Nelson 2000; Powers, 2004;

Smallwood, 2004). In other words, one out of every two students who start a doctoral program do not finish it.

The number of drop-outs may vary according to the university location, the field of study and amount of financial aid granted at the program. One study noted disparity of students dropping according to the location of the university and found out that that attrition rate is about $33 \%$ for departments in rural universities and 68\% for universities at urban universities (Lovitts, 2001). Attrition rates are found to be less than $50 \%$ for scientists and those in medical fields. This is attributed to the fact that these fields receive more grants and financial assistance.

As to the specifics of the numbers, the Digest of Education Statistics for 2002 presents a dire picture about the percentage of students who start high school and, after 10 years, ended up being enrolled in the doctoral programs. It listed that only .2\% (2 in a thousand) of male students and $.1 \%$ ( 1 in a thousand) for female students who started in high school ended up enrolling in a doctoral program (NCES, 2003). So, while only one in a thousand of the population enrolls in a doctoral program, still fewer graduate from such programs. The national science foundation (NSF) indicates that 40,774 doctoral degrees are conferred by doctoral granting institutions in 2001 (Lazerson, 2003). So taking the 50\% that was noted earlier and the number of degrees conferred as reported by the NSF, it means that here are more that 40,000 students who attend doctoral program annually end up dropping out instead of completing the program and obtaining the doctorate degree.

\section{Doctoral Attrition - Reasons}

Peggy Hawlery's (2003) book about the doctoral experience describes the feeling and experience of graduating students as well as those students who do not finish their doctoral degrees:

"The ancient ceremony is repeated annually in thousands of institutions of higher learning throughout the western world. Heavy with the symbolism of medieval scholarship, the conferral of the Degree of Philosophy is public acknowledgement that the recipient has successfully pursued and captured academe's highest award, the terminal degree in a particular field of study.

Yet standing behind each smiling graduate is the shadow of another person who also expected to be there on the auspicious occasion, but dropped out somewhere along the way. Are these "shadow people" intellectually inferior to those who stayed the course and received their Ph.D.? Is the graduation ceremony portrayed here simply an example of Social Darwinism in which only the fittest (brightest) survive?" (p 3)

Hawlery's above statements reflect the general feeling among doctoral faculty as to the main reason why students drop out of doctoral programs - the student's background. Whether it is the background of the students or the amount of effort that was put in by them during the program, some doctoral faculty feel that the basis for student attrition is the student. Therefore, in most cases, the faculty try to tighten the admission requirements for doctoral programs so as to only include those who "are capable to withstand the pressure of the Ph.D. study" (Lovitts, 2001).

However, as efforts were made to tighten admission requirements in a number of doctoral programs, the drop-out rate continued to be high (Lovitts \& Nelson, 2000). The students who usually attend doctoral programs are high achievers who have prior academic experiences that included numerous honors and other evidence of recognized high achievement (Lovitts, 2001). The best and the brightest are among those who drop. 
Barbara Lovitts (2001) outlined three reasons for drop-out among doctoral students:

"It is not the background characteristics students bring with them to the university that affect their persistence outcomes; it is what happens to them after they arrive.

Graduate student attrition is a function of the distribution of structures and opportunities for integration and cognitive map development.

The causes of attrition are deeply embedded in the organizational culture of graduate school and the structure and process of graduate education (p 2)”.

Numerous problems have been cited as reasons that contribute to the high rate of doctoral student drop out. Some reasons are related to the student's life, while others are related to the nature of the doctoral program and its difference to previous studies and programs that were successfully undertaken by the student. A third set of factors lay the blame on the design of the program by not providing a suitable environment for the student to successfully complete their degree (Hawlery, 2003; Lovitts, 2001).

Among the personal reasons that related to the student includes financial issues and family obligations. Doctoral programs are recognized to be a costly process and students usually attend later in their lives where family responsibilities are higher. Thus the sacrifices to the family while necessary, place a strain on the family. As a result, dropping out may be a conscious step taken by the student after ranking the cost and the benefits of such a decision (Hockey, 1994).

But the reasons mentioned above ignore an important factor that deals with the emotional aspect that is normally neglected when talking about doctoral attrition. This emotional aspect is either easily overlooked in the design of doctoral programs or it is not fully addressed in the design of the same programs. Instead, it is left to the individual students to contend with emotional issues on their own (Bess, 1978). Among the emotional issues that are often neglected in doctoral programs is the feeling of isolation that is experienced by the students during their journey to obtain their doctoral degree (Lewis et al., 2005).

\section{Isolation Feelings at Doctoral Programs}

Different studies conducted for the purpose of finding the reasons for attrition among doctoral programs found that isolation remains a prime factor for many students (Hawlery, 2003; Lewis et al., 2005; Lovitts, 2001). This section discusses the feeling of isolation in general. It then illustrates the development of the isolation feeling for students in the four characteristic stages of doctoral programs.

\section{About Isolation Feelings}

The feeling of isolation takes place at different stages in the doctoral program and is manifested in various ways. There are two particular issues that contribute to the development of isolation feeling among doctoral students. First, students begin feeling isolated because of confusion about the program and its requirements. What may start as simple confusion about the program or the requirements of the program quickly grows into a feeling of being left behind and overwhelmed. Second is the lack of (or insufficient) communication that may take place during various phases of the program. Lack of communication takes place on two fronts: student-to-student and student-to-faculty communication. The basis for isolation revolves around these three issues: lack of communications, miscommunication, and confusion. Furthermore, isolation is felt differently at various stages in the doctoral program. To explain about the development phases of isolation feeling, the remainder of this section divides the doctoral degree process into four stages and explains how the isolation feeling is manifested in each stage. 


\section{Stage I - Preadmission to enrollment}

This stage begins early in the process when the student begins inquiring or reviewing pamphlets regarding the doctoral program. Most of the literature directed to this phase describes the preadmission process as vague or unclear at best (Hawlery, 2003; Lewis et al, 2004; Lovitts, 2001). Doctoral manuals and materials do not provide specific requirements as to what needs to be done to complete the degree.

Once a student starts the program, the common complaint that describes their experience is one of "negotiating the system" or "negotiating the relationship with faculty and students" (Lewis et al; 2004). Negotiating the system means lack of knowledge about the procedures and steps taken for the purpose of continuing in the program. Another description of this process is referred to as embarking in a "new territory" because most of the process and procedures of the doctoral program are new and different than what has been previously experienced.

\section{Stage II - First year of program}

Attaining the doctoral degree involves a different journey than prior those taken in the pursuit of bachelors or masters degrees. Therefore, a different set of intellectual and psychological demands is placed on the students. Hawlery (2003) explain the difference of both demands:

"In most disciplines, the Ph.D. is considered a research degree and means that its primary purpose is to not prepare practitioners, clinicians and teachers, but to produce scholars. If you want to be considered scholar, you must do research. This calls for a major transition in how you think and what you do (p. 21)".

"Another important difference between doctoral study and experiences at lower levels education is in the nature and intensity of the psychological demands. It is understandable that academics view the cognitive realm as their primary domain and intellectual accomplishment as their primary mission. Few would argue with this focus. Nevertheless, there are vast differences among faculty in the degree to which they recognize the psychological components implicate it in understanding of this kind. It is subjectively painful experiences that underlie most students' decision to quit, yet many doctoral faculty refuse to concern themselves with that they see as non-cognitive matters (p. 24)".

The two statements above underscore the difficulties that students undergo in adjusting to the new life of doctoral studies. These adjustment difficulties are so pervasive that they last the duration of their program and require a series of major adjustments for each of the different phases of the program. However, the hardest adjustment is encountered during the first year of the doctoral program (Hockey, 1994).

In explaining the experience of the graduate students in their first year, Beeler (1991) described four stages where the actual adjustment occurs for new graduate students. These four stages are first Unconscious Incompetence, second Conscious Incompetence, third Unconscious Competence and fourth Conscious Competence. The four stages introduced by Beeler explain the difficulty and the length of time it takes the students to adjust in their first year.

The adjustment process as noted places a psychological burden that some students may find themselves unprepared for. This combined with the fact that most doctoral departments leave students to deal with the psychological aspects of adjustment to themselves. So the students, who are less prepared for this psychological adjustment, may find themselves left behind, isolated and as a result, may drop out of the program. 


\section{Stage III - Second year through candidacy}

During this stage, doctoral students often take additional courses as required by their program. Their prior experiences in undergraduate and graduate courses as well as the courses they take in the first year may help them to further adjust to the courses they take during their second year. However, students may face two additional major challenges during the second year: first, taking the qualifier or comprehensive exam and second, submitting and defending the project (Dissertation) proposal. This stage may also include selecting a faculty advisor and a dissertation committee.

The qualifier or comprehensive exam basically combines everything the student has taken during the months or years that he/she has been enrolled in the doctoral program, thus the name "comprehensive". It may take several hours and sometimes it may take days to complete. The "comprehensive" nature of the exam makes it more intimidating. This is a milestone "make or break" experience that is usually not faced earlier in the program. Given that each student takes the exam alone, in isolation, it separates each individual student from another contributing to feeling behind, overwhelmed and isolated.

The proposal stage includes selecting a topic of research that will be the focus of the student's research in the dissertation stage. It may also include selecting a faculty advisor, a dissertation committee and doing a proposal presentation in front of the committee. The student is faced with many topics that he/she has had to narrow down in order to reach a topic that is manageable in the eyes of the dissertation committee. Hawlery (2003) explained the difficulty at this stage:

"You are surrounded by ideas, many of which would make an interesting topic. Ideas leap from the printed page, they fall like pearls from the lips of speakers, and a few are even exciting enough to awaken you in the middle of the night, In retrospect, it all seems so simple ... Yet the process of carving a topic from among what seems to be an infinite number of possibilities is anything but simple. Usually it is the result of months of vigorous intellectual effort and considerable emotional investment. Perhaps, the problem is the realization that this innocent-sounding title will have the power to dominate most of your waking hours for several years to come (p 35)".

The uniqueness of the topic of the proposal makes each student experience different from the others. This kind of work forces each student to work alone without the support that they received during prior studies and during their earlier stages of their doctoral study. It potentially leads to confusion and additional psychological pressure. As noted earlier, most doctoral granting departments leave all the aspect of psychological pressure to the students themselves (Bess, 1978).

\section{Stage IV - The dissertation stage}

This is the last stage of the doctoral program in which successful completion results in attainment of the doctoral degree. The steps required to complete this phase of the program vary considerably among doctoral programs and for doctoral candidates. But the processes by which they complete it are complicated, long and daunting. Lovitts (2001) explained about this:

"These are complex processes with which most students have little familiarity or prior experience. Students who reach this stage know (or discover) that they must conduct research that distinguishes them from their peers. Most feel inadequately prepared to do this type of research and find themselves unprepared for the writing in the style required for a dissertation (p 72)".

Time constraints become important at this stage as well. At this stage, students work on their own with the occasional advice by their faculty advisor. As time passes by, the pressure increases on 
the student (Hockey, 1994). Hawlery (2003) noted the importance of the time at this stage and advises students to "guard your time more carefully than your wallet (p.109)".

This stage is characterized by the students working alone with their advisor in the absence of extensive daily social interaction and communication with their peers or with other faculty. This is complicated by the time constraint. In most cases, there is no specific agenda to follow and there are no marks by which the students measure their progress.

The issue is further complicated because each student works alone on his/her research project. This prevents the students from obtaining vital support that could be gained from communicating with other students who may be working on similar projects (Hawlery, 2003). It deprives the students from comparing their work with yardsticks by which they can determine how much has been completed and how much has yet to be done. This in many cases leads the student to feel uneasy about their progress. As time quickly passes by, the student feels behind, overwhelmed and without social support from peers.

\section{Counter Measures to Isolation Feelings in Doctoral Programs}

The previous section explained the factors in doctoral programs that may contribute to feelings of isolation that potentially influence students' decision to leave the program. These factors can be summarized: 1) unclear or vague requirements, and 2) lack of a social support structure or mechanism. The solution may sound simple: Clarify the requirements and then provide social support. But each stage has many intricacies that make its application require additional steps (Maxwell, 2003). This section presents a suggested solution or counter measure. It first explains socialization in general and then talks about the counter measures within each of the stages that were previously suggested.

\section{About Socialization in Doctoral Programs}

Socialization, whether it would be educational or otherwise, leads to more inclusion, support and understanding. Lovitts (2001) explained about this socialization and its' role in the doctoral attrition:
"Atomism and pluralistic ignorance appear to be key factors in attrition. They separate students from each other and from faculty. They interface with the de- velopment of clear understandings of the nature of graduate education. They pre- vent students from finding moral support within the departmental community and student subcultures, and from giving voice to their concerns and discontent. In short, they throw students and their resources for survival. If the forces that di- vide and separate students encourages attrition, then it stands to reason that forces that unite and assimilate students encourages retention (p. 39)"”.

The forces that separate the students referred to in the above statement have been discussed in the previous section of this paper. There are also forces that unite students and these are achieved through means of providing social support (Hawlery, 2003). One way of offering social support is by having the doctoral program department provide a mechanism for socialization between the students themselves and with the faculty.

Bess (1978) noted that the basic attitude in academic institutions is that the faculty members are responsible for the development of academic life of the students, while social development is left up to the students to explore in an out-of-class setting. The study called such orientation and attitudes unfortunate and explained "since faculty can have effects on student development in both cognitive and affective domain (p. 290)". The study further stressed the importance of socializa- 
tion between faculty and students to break the barriers which allows for direct communication and ease the potential tension between them.

Regarding the experience of African American Ph.D students, a particular study stressed the importance of providing a social support and linked such support to increasing the chance of success for African American students. The study noted further:

"Researchers have applied student models that illustrate the interaction between doctoral students' background characteristics and institutional support and their combined effect on measures of doctoral students' success (Lewis et al, 2004, p. 232)".

The above paragraph notes the importance of social support by the institution to break the feeling of isolation among the students to help increase their chance of success. This may take place either by the faculty taking initiatives to promote socialization with the students, or it could take a form by which the institution provides a mechanism for promoting interaction among the students and also with the faculty. But each of the four stages mentioned in the previous section has its own peculiar requirements in order to be helpful to the students. The remainder of this section explains the socialization and other measure that are suggested during each of the four stages.

\section{Stage I - Preadmission to Enrollment}

The basic strategy is to clarify the requirements for completing the doctorate program as much as possible. Campus visits, meeting the doctoral faculty, and a formal orientation are all helpful methods to minimize confusion on part of the students. One particular university went a step further and required the students to attend an "orientation semester". During the orientation semester, the students are introduced to the faculty while procedures and expectations are clarified (Fields, 1998). Spending a semester or a quarter on orientations may seem to be a waste of time for some who are familiar with the process, but it can go a long way for new students who are not fully prepared for the doctoral experience.

The importance of holding orientation sessions is highlighted in a particular study. It explained that as part of the application process the student received a letter briefly explaining the program. However, the student did not have neither the context nor the complete handbook of expectations that they receive during orientation. They also did not have the chance to interact with the officials from the program as they would during the orientation process (Lewis et al, 2004). This kind of orientation leads to reducing the confusion, clarifying expectations and, as a result, reducing isolation that may result from it.

\section{Stage II - First Year of the Program}

Lovitts (2001) noted the importance of integrating new students into the departmental community. She divides the students who attend the doctoral program into two groups: first, the students who come from academia and have some familiarity with the academic life during the doctorate program. Second, are the students who come from a different background, and are not familiar with the academic process of the doctoral program. Lovitts (2001) noted that the second groups of students have greater difficulty in adjusting to the new life. She suggested some methods such as a welcome party, brown bag lunches and other means of increasing interaction among the students. 


\section{Stage III - Second Year through Candidacy}

At this stage, although the students may take courses together, it marks the beginning of the students to start working alone. Furthermore, two milestones are met in this time frame. These include taking the comprehensive exam and preparing the research proposal.

This stage may also mark the formation of unofficial (or informal) groups within the students (Hawlery, 2003). The formation of the group may be left to the students because the departments often assign projects to individual students - the students form groups to survive. Two studies were conducted to investigate the group dynamics and their effect on degree progress.

The first study was about the supervision of doctoral program using a collaborative cohort model (Burnett, 1999). The study noted that some of the psychological barriers that the students faced during their doctoral program contributed to their decision to leave the program. But the study noted further that developing a cohort model establishes some form of communication that eases the tension and removes some of these psychological barriers. Furthermore, in the collaborative cohort model, groups are formed to exchange ideas about various aspects of the doctoral program (including dissertation and proposal) and are usually supervised by a faculty member.

The second study conducted to explain about group dynamics in the formation of a Ph.D. cohort (Kruppa \& Meda, 2005). It concluded that organizational socialization adds an element of inclusion to its participants. This kind of inclusion was important to the success of the group that it studied. The feeling of inclusion becomes paramount as the student begins working on their individual project.

\section{Stage IV - Dissertation Stage}

The group dynamics and the cohort approach that was suggested in the previous step may be more helpful to the students at the dissertation stage. However, the dissertation stage has its own characteristics that may require taking additional measures to be helpful to the students.

A particular program that follows the constructivist model lets the students publish their work in a common website so each of the other one can gauge his or progress toward completing the dissertation (Lazerson, 2003). Using this approach, the students may provide feedback to each other's dissertations helping to identify and remedy problems as soon as possible. This policy helped the students feel less isolated, and, as a result, some of them were able to finish their dissertation at a faster pace.

Identifying specific steps for the completion of the dissertation and setting target deadlines for each step helps ensure on-time completion and minimizes waiting time.

\section{The Doctoral Program at RMU}

The Doctorate of Science in Information Systems and Communications program at Robert Morris University (RMU) started in 1999 (Robert Morris University, 2004). This program was able to graduate students at higher rate and with less time than the national average. Over the six years since this program started, the rate of graduation in this three year program was above $90 \%$. In a prior study conducted by the authors of this paper, the success of the graduation rate and time of completion was attributed to the following factors (Kohun \& Ali, 2005b):

1- Three years lock-step program: The program is designed to be completed in three years. The students take specified number of courses each semester and registration and all administration procedures are taken care by staff from the university. 
2- Cohort approach: The students are accepted as cohorts. All students in a given cohort start the program at the same time, take the same courses each semester and are supposed to complete the program together.

3- Residency week and weekends: The program is taught in a residency week at the beginning of the semester and three residency weekends during the semester. Students stay at a nearby hotel to simplify commuting from the hotel to the university to take courses all day long during their residencies.

Further, a survey conducted for three cohorts enrolled in the program found out that the students enrolled in the program recognized the role that the feeling of isolation had on their studies. The students further felt that the residency program and the cohort approach helped minimize isolation feeling among the students (Kohun \& Ali, 2005a). But the program involves more than the above steps. It has numerous design characteristics that addresses the issues brought up at each of the four stages that were mentioned earlier in this paper.

\section{Stage I - Preadmission to Enrollment}

As part of the admission requirements to this program, the students are invited for a campus interview. During the campus visit, all faculty members of the program are invited to the interview - an opportunity to exchange ideas between the prospective student and the faculty. The student is then taken on a tour of the campus and all procedures are explained.

The start-up time is the time to acquaint the students with the staff and the administrative procedures. This is accomplished during the first residency week. Administrative staff as well as the faculty from the involved departments are invited to introduce themselves. Most of the administrative procedures like registration, billing, and ID are completed by a staff member from the program.

\section{Stage II - First Year through Candidacy}

During the first doctoral residency week, students are introduced to each other as well as to all the faculty and administrators. Upper administrators including the provost and dean greet the students and respond to questions. An orientation party is held on the first Friday of the residency week. The party invites various faculty and administrators. The other two cohorts in the program (second and third year students) are invited also. This encourages newer students to communicate with students from earlier experienced cohorts.

The residency week makes it easier for the students to communicate with each other. Furthermore, two additional activities are commonly held at the hotel where the students are staying: study \& discussion and debriefing. Communication is encouraged on two fronts: student-tostudent communication and student-to-faculty communication. At the end of the first year, the students take the qualifier exam that enables them to continue the program.

\section{Stage III - Second Year to Candidacy}

The second year of this program includes taking courses, submitting a proposal for the field project (dissertation) and then selecting a committee for the selected research topic. The activities mentioned earlier that include community dinner, debriefing, and others are present at this stage as well. But additional steps are introduced here to face the newer situation of the submitting and having the research proposal approved.

The proposal includes the selection of a topic that will be used for further research at the dissertation stage. Numerous steps are taken by the program to help the students refine the selected topic to make it more suitable for the dissertation stage. These steps include: Meeting privately with 
two faculty members, presenting the topic in front of the cohort and other faculty, meeting with perspective faculty advisor and committee members and then defending the proposal in front of the committee.

At the beginning of the semester, the students are asked to submit a proposal for a topic that will be used for their dissertation. The students meet individually with two faculty members to ensure that the methodology is well defined and appropriate: one faculty is responsible for the quantitative methodology and the other for the qualitative methodology. The private meetings take place and the intricate details of the proposal are discussed to suggest whether it will be a quantitative study or it is qualitative one. Further efforts are made to narrow down the topic so it would manageable and suitable for a dissertation project.

All students are required to publicly present their proposal topic to their cohort. Other faculty may attend the presentation. The presentation is designed so the students get feedback and suggestions for improvement in the proposal.

Selecting a committee is based on the subject matter of the proposal, the background of the faculty advisor, as well as the background of the other faculty in the committee. Once the committee is selected, the student communicates directly with them in order to prepare for defending the proposal. The proposal is formally developed at this stage to include the statement of the problem, the methodology, data collection methods and others. Once the student defends the proposal successfully, he or she will be ready for the dissertation stage.

\section{Stage IV - Dissertation Stage}

The dissertation stage includes communicating directly with the faculty advisor and with the committee members. This is the stage where the isolation is normally the most intense because communication is limited to only a few individuals. Nevertheless, this program attempts to overcome this problem as well. The community dinners and debriefings continue at the same time which enhances communication both between the students and with the faculty. Further, face-toface meetings are mandated between the students and each member of the committee. Each of the residencies during the last semester is specified for the student to meet individually with the committee. Also, the student presents his/her dissertation to their fellow cohort at every stage. Feedback is plentiful at these presentations to help refine the project and transform it into final form before presenting it to the committee.

\section{About Program Quality}

While designing a program that uses the constructivist model and emphasizes socialization, questions may be raised regarding program quality. This is peculiar to the program at Robert Morris University. Skeptics may raise questions regarding the quality of the program and may think that the research quality of the program has been compromised. Thus this section tackles the issue of the quality of doctoral programs and how they are ranked.

The National Research Doctorate issues a table ranking doctorate programs in the US every ten years (National Research Council, 1995). The last one was due in 2005 but due to many difficulties, the report was postponed for another year (Broida, 2004). As a result, the latest official survey or ranking of doctoral programs was not available at the time of writing this paper. However, it should be noted that the National Research Doctorate uses specific criteria to judge the quality of the doctoral programs. Additionally, in another study conducted by Kohun \& Ali (2005b) that compared the information systems doctorate degrees offered at universities in the state of Pennsylvania, the study concluded that there was no major difference in the criteria of the program at RMU and the comparable programs in the eight universities in Pennsylvania that were evaluated. 
The study further found that the number of courses, the research courses and other factors are comparable to the other seven programs in the state of Pennsylvania.

\section{Summary and Future Work}

This paper is about isolation feelings among doctoral students and their contribution to attrition in doctoral programs. It started by explaining about doctoral attrition in numbers and reasons. It then divided the development of isolation to four stages. It then suggested some counter measures or solutions for institutions to follow which may lead to the minimization of isolation. It further focused on the experience of the doctoral program of Information Systems and Communication at Robert Morris University that had a successful experience at graduating a number of doctoral students at a rate substantially higher than the national average. Lastly, the paper addressed the issue regarding program quality.

The stages that are covered here lead to the creation of a model that addresses this issue. There are enough materials that were retrieved for this paper and there is a need for developing a model that addresses isolation feeling at doctoral studies. The next paper builds on the findings of this paper and continues on building a model for dealing with isolation feeling at doctoral programs.

\section{References}

Beeler, K. D. (1991). Graduate student adjustment to academic life: A four-stage framework. NASPA Journal, 28(2), 163-171.

Bess, J. L. (1978). Anticipatory socialization of graduate students. Research in Higher Education, 8, 289317.

Broida, B. (2004). 'Gold standard' for rating doctoral programs is stalled. The Chronicle of Higher Education; 50(31), A10-A11.

Bourner, T., Bowden, R. \& Laing, S. (2001). Professional doctorates in England. Studies in Higher Education, 26(1). Retrieved from EBSCOHost on 2/18/04.

Bowen, W. C. \& Rudenstine, N. L. (1992). In pursuit of the PhD. Princeton, NJ: Princeton University Press.

Burnett, P. C. (1999). The supervision of doctoral dissertation using a collaborative cohort model. Counselor Education and Supervision; 39(1), 46-52.

Fields, C. D. (1998). Making mentorship count: Surviving Ph.D. programs requires someone who is willing to show the way. Black Issues in Higher Education; 15(3), 28-30.

Hawlery, P. (2003). Being bright is not enough. Springfield, IL: Charles C Thomas.

Hockey, J. (1994). New territory: Problems of adjusting to the first year of a social science PhD. Studies in Higher Education; 19(2), 177-190.

Kohun, F. \& Ali, A. (2005a). An IS doctoral degree program of a kind. Issues in Information Science and Information Technology. 2, 179-188. Available at http://proceedings.informingscience.org/InSITE2005/I15f26Kohu.pdf

Kohun, F. \& Ali, A. (2005b). Isolation feelings in doctoral programs: A case study. Issues in Information Systems; VI (1), 379-385.

Kruppa, R. \& Meda, A. K. (2005). Group dynamics in the formation of a PhD cohort: A reflection while learning organizational development theory. Organization Development Journal; 23(1), 56-67.

Lazerson, M. (2003). Navigating the journey: A case study of participants in a dissertation support program. Doctoral Dissertation, University of Pennsylvania. 
Lewis, C. W., Ginsberg, R., Davies, T., \& Smith, K. (2004). The experiences of African American PH.D. students at a predominantly white Carnegie I - research institution. College Student Journal; 38(2), 231-245.

Lovitts, B. E. (2001). Leaving the Ivory Tower: The causes and consequences of departure from doctoral study. Lanham, MD: Rowman \& Littlefield.

Lovitts, B. E. \& Nelson, C. (2000). The hidden crisis in graduate education: Attrition from PhD programs. Retrieved January 27, 2005 from http://www.aaup.org/publications/academe/2000/00nd/ND00LOVI.HTM

Maxwell, Tom (2003). From first to second generation professional doctorate. Studies in Higher Education Volume 28, No. 3 August.

Mehmet, H. A. \& Ekrem, M. (2000). Assessing supervision requirements of PHD students: The case of construction management and engineering in the UK. Journal of Engineering; 25:1. Retrieved from EBSCOHost on 2/2/04.

National Center for Education Statistics [NCES], (2003). Digest of Education Statistics 2002. Washington, DC, National Center for Education Statistics.

National Research Council. (1995). Research-doctorate programs in the United States: Continuity and change. National Academy Press, Washington DC.

Powers, L. (2004, October 29). Doctoral dilemma: Half of all Ph.D. Candidates drop out, wasting resources. Reno Gazette-Journal. Retrieved November 15, 2004 from http://www.rgj.com/news/stories/html/2004/10/29/84016.php.

Robert Morris University. (2004). www.rmu.edu Doctoral program at a glance. Accessed on 2/23/04.

Smallwood, S. (2004) Survey points to mismatch in doctoral programs The Chronicle of Higher Education; 47(20), A14-A15.

\section{Biographies}

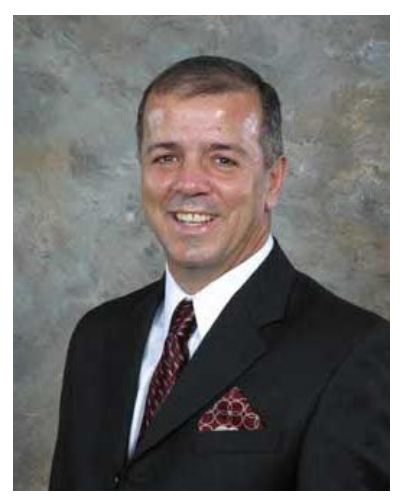

Azad Ali, D.Sc., Associate Professor of Technology Support and Training at Eberly College of Business - Indiana University of Pennsylvania has 22 years of combined experience in areas of financial and information systems. He holds a bachelor degree in Business Administration form the University of Baghdad, an M.B. A. from Indiana University of Pennsylvania, an M.P.A. from the University of Pittsburgh, and a Doctorate of Science in Communications and Information Systems form Robert Morris University. Dr. Ali's research interests include object oriented languages, web design tools, and curriculum design. His community service and academic expertise gets him in the news on Pittsburgh television and in the newspapers.

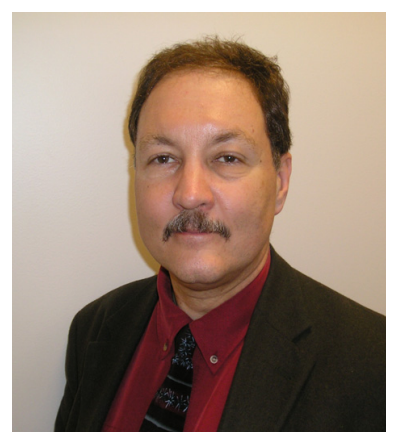

Frederick G. Kohun, Ph.D., Associate Dean and Professor in the School of Communications and Information Systems at Robert Morris University in Pittsburgh, has more that 29 years experience as a professor and administrator in the information systems field. He holds a bachelor degree in economics from Georgetown University, graduate degrees in economics and information science, from the University of Pittsburgh, and a Ph.D. in applied history in technology from Carnegie Mellon University. He had a leadership role in the design and implementation of eight technology based academic programs at the undergraduate and graduate level including a doctoral program. Most recently, he was involved in the first round of ABET-CAC information systems accreditation. 